UDC 536.631

\title{
INVESTIGATION OF THE THERMOPHYSICAL CHARACTERISTICS OF MINERALS AT VARIOUS HEATING PARAMETERS
}

\author{
Shaimerdenova K.M., Stoev M., Sekerbayeva G.K., Bulkairova G.A., \\ Ospanova D.A., Tussypbayeva A.S., Rakhmankyzy A.
}

\author{
1E.A. Buketov Karaganda University, Karaganda, Kazakhstan,
}

\begin{abstract}
The study of natural minerals in the production of heat and electrical insulating materials is of particular practical interest for the study of their thermophysical characteristics. The regularities of changes in the heat capacity of minerals when heated in production and operating conditions are of particular interest. Natural minerals of wollastonite and quartz were considered as the object of research. The heat capacity of these minerals was measured in an apparatus with a three-dimensional sensor and a panel for automatic control of gas flows, when heated to the temperature of $1600^{\circ} \mathrm{C}$ by the calorimetric method. Based on the experimental results, graphs of the dependence of the heat capacity of mineral samples on temperature were constructed.
\end{abstract}

Keywords: wollastonite, quartz, differential scanning calorimetry, heat capacity, thermal condition.

\section{Introduction}

The problem of theoretical and experimental study of the properties of natural minerals remains relevant. To know the thermo-physical properties of substances under different variable temperature conditions is important for several reasons. Here it is important to define the thermo-hysical characteristics of natural minerals, those of building, heat-insulating, facing materials and products and their recyclability. The thermo-physical characteristics of closed structures affect the thermal and air conditions of buildings for various purposes, as well as ventilation and air quality, which currently consume a significant amount of thermal energy, as well as the operation of heating systems.

One of the most promising areas of science and practice for improving the grinding process is targetspecific changing the properties and state of natural minerals [1]. Stationary, non-stationary and complex methods based on the theory of thermal conductivity are used to determine the thermo-physical characteristics of minerals and materials in stationary or non-stationary thermal conditions. In addition, these methods can be absolute and relative [2]. Natural minerals are widely used as heat insulators in metal smelting, heating, various wall-mounted boilers, and electric heaters. In foundry and metallurgy, heatresistant molding materials, especially in powder form, diatomaceous earth and other refractory materials are used. The extraction of high-melting and heat-resistant minerals in the Republic of Kazakhstan is of particular interest. Currently, the minerals of the Republic of Kazakhstan are used for the manufacture of raw bricks, houseware, souvenirs, various parts of electric stoves, ovens, etc. [3, 4].

\section{Experimental part}

The heat capacity of the whole body is taken into account when studying the structure of substances and their properties, studying phase transitions and critical phenomena, calculating the total amount of impurities in a substance, determining the thermal effects of chemical reactions. In addition, heat capacity as a thermophysical parameter is an effective tool for scientific research. The determination of the heat capacity of natural minerals was carried out in the LABSYS ${ }^{\mathrm{TM}}$ EVO apparatus with synchronous thermo-gravimetric, differential thermal analysis, a 3D sensor at a temperature of up to $1600^{\circ} \mathrm{C}$ and an automatic gas flow control panel (LABSYSTM EVO TG, DTA, DSC $1600{ }^{\circ} \mathrm{C}$ ) in the "Methods of physical and chemical research" engineering laboratory of Karaganda E.A. Buketov University (Fig. 1) [5]. 


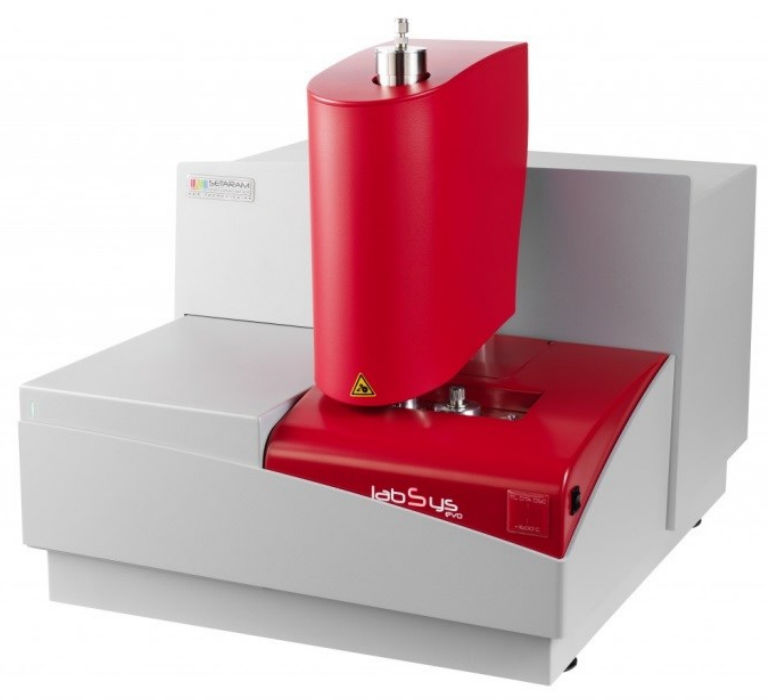

Fig.1. LABSYS ${ }^{\mathrm{TM}}$ EVO thermal analyzer (main view)

The work is carried out as follows: using a laboratory balance, the mass of the studied minerals is determined: wollastonite, quartz samples from two deposits (Aktas) and (Nadyrbai). The sample weights are, respectively, equal: wollastonite $-8 \mathrm{mg}$, quartz (Aktas) - $9.36 \mathrm{mg}$, and quartz (Nadyrbai) - $9.6 \mathrm{mg}$.

Differential Scanning Calorimetry (DSC) is a method in which the difference in heat flows applied to the crucible with the test sample and the reference crucible is measured as a function of temperature and/or time during the exposure of the test and reference samples to a controlled temperature program under a specified atmosphere and using symmetrical measuring system. The use of DSC makes it possible to significantly reduce the time for conducting experiments and to obtain experimental data on the specific heat capacity of the investigated products with an error of no more than $3 \%$.

Two valved crucibles are placed in the DSC measuring chamber, the test sample is placed in the first one, and the second is used as a reference (free) crucible. The material of the crucible is set depending on the maximum heating temperature of the sample and the tested substance, which should not react with the crucible. In the experiment, platinum was used (up to $1000^{\circ} \mathrm{C}$ ) as the crucible material. The experimenters run the apparatus program and set the parameters to perform the required thermal scanning. During the experiment the program of continuous heating was used. After starting the device, measurements were taken.

The temperature was determined using the thermocouples in the measuring chamber of the calorimeter. When the sample begins to heat up, heat is released. Then the system can measure and analyze the change in specific heat. The melting points of the tested natural minerals were obtained from the reference data. Accordingly, the melting points of minerals are: wollastonite $-1400-1500^{\circ} \mathrm{C}$, quartz (Aktas) $-1710-1720^{\circ}$ $\mathrm{C}$, quartz (Nadyrbai) $-1710-1720^{\circ} \mathrm{C}$. These values are necessary so that when minerals are heated, their temperature values exceed the specified range.

Specific heat $c_{p}, \mathrm{~J} / \mathrm{g} \cdot \mathrm{K}$ is calculated by the formula

$$
c_{p}=m^{-1} C_{p}=m^{-1}(d Q / d T)_{p},
$$

where $m$ is the mass of the sample, $\mathrm{g} ; C_{p}$ is the heat capacity, $\mathrm{J} / \mathrm{K} ; d Q$ is the amount of heat, $\mathrm{J}$, required to increase the temperature of the material by $d T, \mathrm{~K}$.

The subscript indicates an isobaric process. According to experiment, the specific heat capacities of natural minerals are determined by the proposed formula (1), which represents the amount of heat absorbed by a unit mass of material when heated by $1 \mathrm{~K}$ at constant pressure. By calculating the dependence of the specific heat capacity of mineral samples on temperature are obtained.

\section{Discussion of results}

Using the results obtained, a graph of the dependence of the specific heat capacity on temperature $c=f(T)$ is plotted. The experimental values of the heat capacity of minerals are given in Table 1 . The plot of the obtained heat capacity versus temperature for wollastonite under the thermal condition is shown in Fig. 2. 
Table 1. Experimental values of the heat capacity of minerals

\begin{tabular}{|l|l|l|l|l|l|}
\hline \multicolumn{2}{|c|}{ Wollastonite } & \multicolumn{2}{c|}{ Quartz (Aktas) } & \multicolumn{2}{c|}{ Quartz (Nadyrbay) } \\
\hline $\mathrm{T}, \mathrm{K}$ & $\mathrm{c}, \mathrm{J} / \mathrm{g} \cdot \mathrm{K}$ & $\mathrm{T}, \mathrm{K}$ & $\mathrm{c}, \mathrm{J} / \mathrm{g} \cdot \mathrm{K}$ & $\mathrm{T}, \mathrm{K}$ & $\mathrm{c}, \mathrm{J} / \mathrm{g} \cdot \mathrm{K}$ \\
\hline 304.7 & -0.108 & 305 & -0.083 & 305 & -0.146 \\
\hline 361 & 0.31 & 361 & 0.038 & 361 & 0.072 \\
\hline 449 & 0.414 & 449 & 0.093 & 450 & 0.128 \\
\hline 539 & 0.376 & 539 & 0.095 & 539 & 0.143 \\
\hline 627 & 0.405 & 627 & 0.148 & 627 & 0.208 \\
\hline 713 & 0.333 & 713 & 0.121 & 713 & 0.237 \\
\hline 798 & 0.293 & 798 & 0.125 & 797 & 0.166 \\
\hline 881.7 & 0.317 & 882 & 0.204 & 882 & 0.238 \\
\hline 964 & 0.332 & 964 & 0.259 & 964 & 0.288 \\
\hline 1045.7 & 0.406 & 1046 & 0.328 & 1045.5 & 0.348 \\
\hline 1126 & 0.471 & 1126 & 0.427 & 1125.8 & 0.412 \\
\hline 1205 & 0.508 & 1205 & 0.44 & 1205 & 0.455 \\
\hline 1284 & 0.542 & 1284 & 0.445 & 1284 & 0.504 \\
\hline 1293 & 0.552 & 1293 & 0.449 & 1293 & 0.508 \\
\hline
\end{tabular}

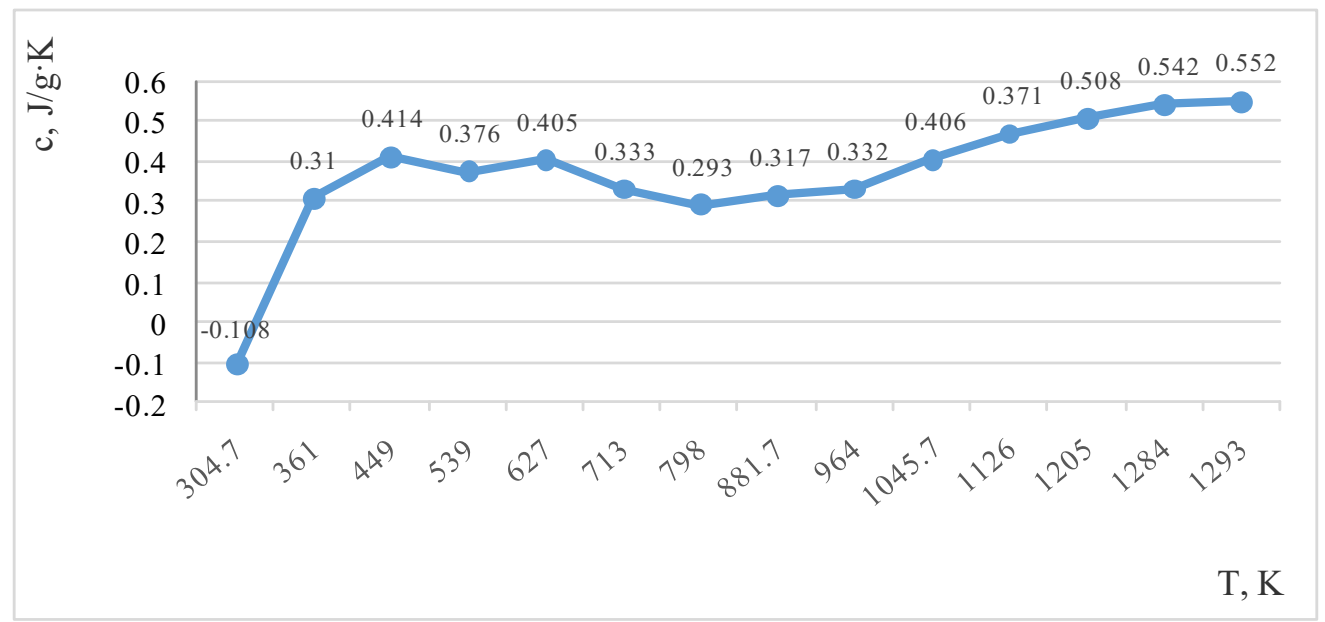

Fig.2. Dependence of the heat capacity of wollastonite $c=f(T)$ under heating process.

As can be seen from this graph, the heat capacity values with in the temperature range from $304 \mathrm{~K}$ to $1293 \mathrm{~K}$ vary from 0.108 to $0.552 \mathrm{~J} / \mathrm{g} \cdot \mathrm{K}$. The specific heat capacity for the temperature condition of wollastonite within the temperature range of $1193-1293 \mathrm{~K}$ is calculated by the equation (1):

$$
c=\frac{(d Q / d T)_{p}}{m}=\left(\frac{(6.14-5.216)}{(1293.82-1193.43)}\right) / 0.008=1156.3 \mathrm{~J} / \mathrm{kg} \cdot \mathrm{K} .
$$

The graph of the temperature dependence of the heat capacity obtained for quartz (Aktas) under thermal condition is shown in Figure 3. As can be seen from the graph, the heat capacity values with in the temperature range from $305 \mathrm{~K}$ to $1293 \mathrm{~K}$ were $-0.083-0.449 \mathrm{~J} / \mathrm{g} \cdot \mathrm{K}$.

The specific heat capacity of the quartz (Aktas) under thermal condition within the temperature range $1123-1293 \mathrm{~K}$ is calculated: 


$$
c=\frac{(d Q / d T)_{p}}{m}=\left(\frac{(6.16-5.45)}{(1293.91-1193.11)}\right) / 0.00936=752.88 \mathrm{~J} / \mathrm{kg} \cdot \mathrm{K}
$$

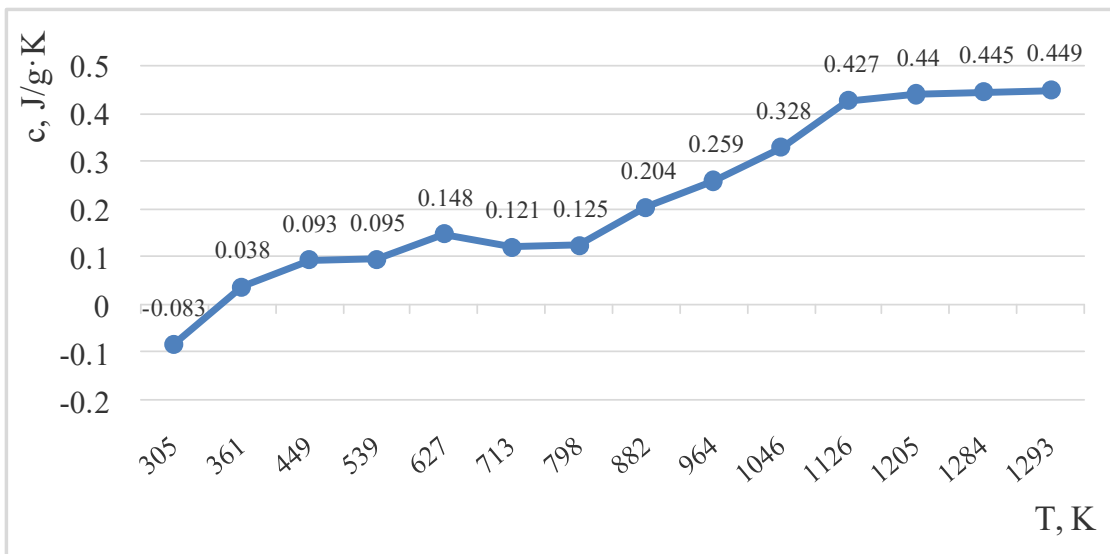

Fig.3. Graph of dependence $c=f(T)$, obtained for quartz (Aktas) under thermal condition

The graph of the temperature dependence of the heat capacity, obtained for quartz (Nadyrbay) under thermal condition, is shown in Figure 4.

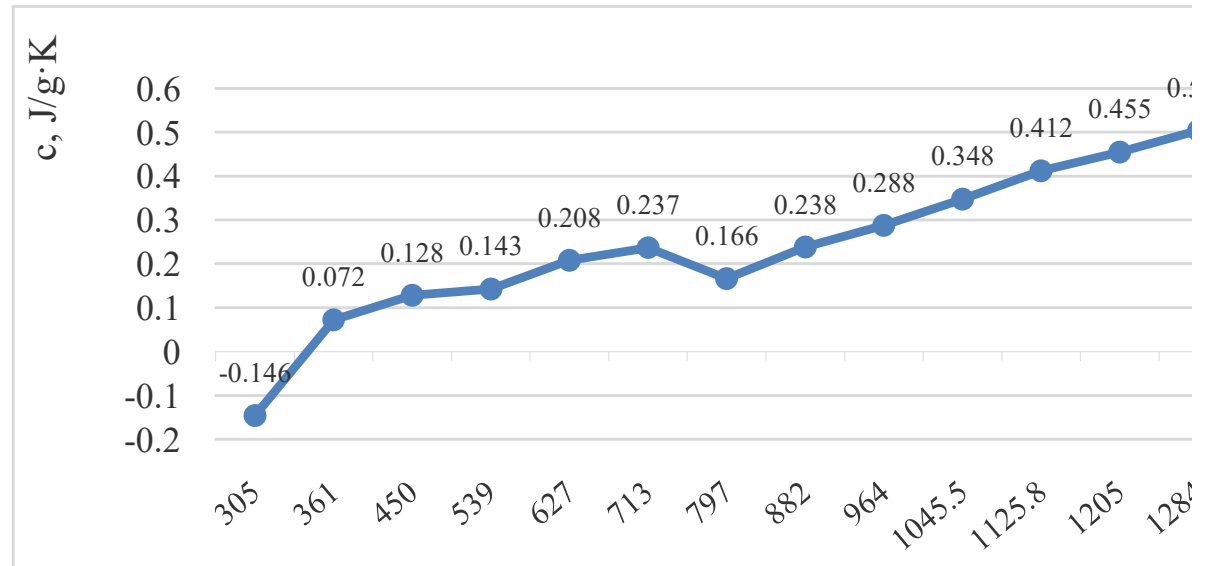

Fig.4. Graph of dependence $c=f(T)$, obtained for quartz (Nadyrbay) under thermal condition

Figure 4 shows that the heat capacity values with in the temperature range from $305 \mathrm{~K}$ to $1293 \mathrm{~K}$ are $0.146-0.508 \mathrm{~J} / \mathrm{g} \cdot \mathrm{K}$, respectively. The heat capacity of quartz (Nadyrbay) under the thermal condition within the temperature range of $305-1293 \mathrm{~K}$ is calculated by the equation (1):

$$
c=\frac{(d Q / d T)_{p}}{m}=\left(\frac{(6.87-0.44)}{(1293.59-305.35)}\right) / 0.0096=770.7 \mathrm{~J} / \mathrm{kg} \cdot \mathrm{K} .
$$

After the experiments, the average values of the specific heat capacity with an error of $0.08 \%$ were determined and compared with theoretical values $[7,8]$, which are given in table 2 .

Table 2. Comparison table

\begin{tabular}{|l|c|c|c|}
\hline \multicolumn{1}{|c|}{ Mineral } & $\begin{array}{c}\text { Wollastonite, } \\
\mathrm{c}, \mathrm{J} / \mathrm{kg} \cdot \mathrm{K}\end{array}$ & $\begin{array}{c}\text { Quartz (Aktas), } \\
\mathrm{c}, \mathrm{J} / \mathrm{kg} \cdot \mathrm{K}\end{array}$ & $\begin{array}{c}\text { Quartz (Nadyrbay), } \\
\mathrm{c}, \mathrm{J} / \mathrm{kg} \cdot \mathrm{K}\end{array}$ \\
\hline Experimental values & 1156.3 & 752.88 & 770.7 \\
\hline Theoretical values & 1100 & 692 & 692 \\
\hline
\end{tabular}


It can be concluded from the table that the experimental values correspond to the theoretical ones. As can be seen from the temperature-dependent graph $c=f(T)$ of the heat capacity for wollastonite, quartz and dolomite under thermal condition, as the temperature rises, the heat capacity increases accordingly. The observation showed that the specific heat capacity of natural minerals depends on the temperature and concentration of the main components.

\section{Conclusions}

The specificity of the theory of thermal condition is that its basic conditions are generalized to the conditions for the existence of bodies of complex composition (systematic) and of any shape, while the usual theory is limited to the study of simple temperature fields or sometimes two-component bodies of a simple shape. Using DSC, the specific heat capacity of natural minerals with an error of $0.08 \%$ was determined. Specific heat capacity values are important material characteristics for their research and development as well as for quality control. The developed methods can be applied in information-measuring systems of thermophysical characteristics, in practice for thermophysical measurements, and in construction heat engineering.

\section{REFERENCES}

1 Sidortsova L.S. Current state and trends in the development of intellectual property in the field of physical and technical control of properties and state of rocks. Mining Informational and Analytical Bulletin, Moscow. 2009. No. 3 , pp. $141-145$.

2 Fokin V.M., Kovylin A.V., Chernyshov V.N. Energy-efficient methods for determining the thermophysical properties of building materials and products. Moscow, Publishing House "Spectr", 2011. 156 p.

3 Deveterikova M.I., Kozina L.N. Laboratory practicum on general heat engineering. Togliatti, 2007, 427 p.

4 Skryabin V.I. A series of lectures on heat engineering. Russian University of physics and technology. 2000, 82p.

5 State standard 55134-2012 (ISO 11357-1: 2009) Plastics. Differential Scanning Calorimetry (DSC). Part 1. General principles. Moscow, 2014, 27 p.

6 State standard 56754-2015 (ISO 11357-4: 2005) Plastics. Differential Scanning Calorimetry (DSC). Part 4. Determination of specific heat capacity. Moscow, 2017. $17 \mathrm{p}$.

7 Babichev A.P., Babushkina N.A., Bratkovsky A.M., et al. Physical quantities. Reference guide. (Ed. by Grigorieva I.S., Meilikhova E.Z.). Moscow, 1991, 1232 p.

8 Dobrynin V.M., Vendelstein B.Yu., Kozhevnikov D.A. Petrophysics (Physics of rocks). Textbook for universities. Moscow, Gubkin Russian State University of Oil and Gas, 2004, 368 p. [in Russian] 